\title{
Antifungal properties of seeds Cassia tora Linn
}

\begin{abstract}
The antifungal activities of extracts in organic solvents from seeds of Cassia tora were tested. Based on the polarity, three organic solvents like Petroleum Ether, Chloroform and Methanol were used for preparing the extracts $(1.0 \%$ and $1.5 \%)$ from the stem and seeds of C. tora against three common forest fungi viz. Colletotrichum gloeosporiodes, Fusarium oxysporum and Ganoderma lucidum. The inhibitory activity of all the extracts against three fungi remained consistently high in the chloroform extract i.e., $36.2 \%, 31.9 \%$ and $36.2 \%$ for $C$. gloeosporiodes, $F$. oxysporum and $G$. lucidum respectively; next effective reagent was Petroleum Ether. In general, higher concentration of extract $(1.5 \%)$ was found to be more effective against all three fungi than lower concentration of $1.0 \%$. Chloroform extract (1.5\%) was found to be most suppressive of C. gloeosporiodes. (65.4 and 68.4\%) than other fungi, while Petroleum Ether $(1.5 \%)$ was found to be reasonably inhibitory $(57.3 \%)$ to $F$. oxysporum. It may be concluded from these observations, that concentration of stem and seed extracts from $C$. tora may change the extent of fungal growth thus crucial to realistic screening.
\end{abstract}

Keywords: Antifungal, Cassia tora, Colletrotrichum gloeosporiodes, Fusarium oxysporum and Ganoderma lucidum
Volume 2 Issue $6-2018$

\author{
Poonam Dubey, Rupnarayan Sett \\ Tropical forest research institute, India
}

Correspondence: Rupnarayan Sett, Tropical forest research institute, I A/8 KesarVihar, New Ram Nagar, Adhartal, Jabalpur 482004, 2 V/9 New Colony, India,

Email rupporan200I@yahoo.co.in

Received: September 26, 2018 | Published: November 13, 2018

\section{Introduction}

Approximately 2,400 species of plants possess pesticidal properties. ${ }^{1}$ Cassia tora belongs to the family Leguminosae. It is an annual monsoon weed prevalent in wastelands having antimicrobial properties. $^{2}$ The ecofriendly antimicrobial properties of its seed gum has been reported by different workers. ${ }^{3-5}$ Keeping the problem of pollution and health hazards of conventional agrochemicals in view, a study was conducted to test its seed-extract against the common aerial fungus (Colletotrichum gloeosporioides), soil-fungus (Fusarium oxysporum) and root-rot-fungus (Ganoderma lucidum) found abundant in forest ecosystem. Arrays of seed-extract with varied concentrations of Cassia tora in different organic solvents were screened to identify the maximum antifungal activity.

\section{Material and methods}

\section{Plant extracts and test fungi}

The seed of Cassia tora was shade dried and powdered; the seedpowder was again shade-dried. $3 \mathrm{~kg}$ of seed-powder was defatted with Petroleum Ether and then extracted with 5 liter of 95\% Methanol, Petroleum Ether or Chloroform at $40-60^{\circ} \mathrm{C}$ in Soxhlet apparatus for 17 hours. The respective extracts were then suspended in 1 liter $\mathrm{H}_{2} \mathrm{O}$.

Chloroform, Petroleum Ether and Methanol extracts of seeds of Cassia tora were then tested for their efficacy on the fungi Colletrotrichum gloeosporioides, Fusarium oxysporum and Ganoderma lucidum. The initial screening was done at $0.5 \%$ concentration of extracts of both stem and seed. At later stage, only chloroform and petroleum ether extract of seeds were tested at 1.0 and 1.5 percent concentration.

\section{Detoxification assay}

The principle involved in this technique is to toxify the nutrient medium with a fungi toxicant and then allowing a test fungus to grow on such a medium. Potato-dextrose agar medium was prepared in flask and sterilized. The petri plates having $7 \mathrm{~cm}$ inner diameter were used. $130 \mathrm{ml}$ sterilized PDA containing $0.7 \mathrm{gm} / \mathrm{ml}$ extract were poured aseptically in nine plates. After solidification, small $(0.7$ $\mathrm{mm}$ ) agar disc of 7 days old activated culture were placed in the center with the help of sterile cork-borer. Control experiments were undertaken parallelly like PDA + Fungus without addition of seedextract, Solvents (Acetone and Methanol) + Fungus without addition of seed-extract. The diameter of the colonies were compared with these controls to determine the extent of fungitoxicity of seed-extract from Cassia tora.

The percentage of inhibition was calculated using the following formula:

$$
\mathrm{I}=\frac{\mathrm{C}-\mathrm{T}}{\mathrm{C}} \times 100
$$

Where, I=Percent Growth Inhibition; $\mathrm{C}=$ Radial Growth in $\mathrm{cm}$ of Test Fungus in control Petri plate; $\mathrm{T}=$ Radial Growth in $\mathrm{cm}$ of Test Fungus in treated Petri plate

\section{Statistical analysis}

Data were statistically analyzed using SPSS 11.0 (Statistical Package for Social sciences). Experiments of antifungal activities were analyzed by two way factorial models. The significance of difference between the treatments was tested at tested at 5\% level of significance.

\section{Results}

\section{Inhibitory activity of Cassia tora seed-extract against Colletotrichum gloeosporioides}

It was observed that than that of seed extract (2.6\%), stem extract of Cassia tora had significantly more antifungal activity (14.3\%) (Table 1), irrespective of nature of extract used. Highest activity was found in the Chloroform extract (21.7\%) followed by Petroleum Ether $(18.2 \%)$. Least antifungal activity was quantified in the Methanol extract $(10.2 \%)$, irrespective of plant part tested. While studying interaction between the plant part and extract $(\mathrm{P} \times \mathrm{T})$, it was found that 
significantly more activity was present in Chloroform extract of stem (36.2\%) followed by Petroleum Ether (29.9\%). Methanol extract had least antifungal activity $(20.5 \%)$ and very low activity in all the seed extract $(7.1 \%$ in case of Petroleum Ether as well as for Chloroform extract).

Table I Percent of inhibition of growth of Colletotrichum gloeosporiodes with different extracts at $0.5 \%$ of stem and seed of Cassia tora

\begin{tabular}{lllllllll}
\hline Part & \multicolumn{2}{l}{ Treatments } & & & & & Mean \\
\hline & CK & CKA & CKM & PE & CHL & ME & \\
\cline { 2 - 7 } Stem & $0.0^{\mathrm{a}}$ & $0.0^{\mathrm{a}}$ & $0.0^{\mathrm{a}}$ & $29.9^{\mathrm{b}}$ & $36.2^{\mathrm{bc}}$ & $20.5^{\mathrm{d}}$ & 14.3 \\
Seed & $0.0^{\mathrm{a}}$ & $0.0^{\mathrm{ab}}$ & $1.4^{\mathrm{c}}$ & $7.1^{\mathrm{c}}$ & $7.1^{\mathrm{cd}}$ & $0.0^{\mathrm{e}}$ & 2.6 \\
Mean & 0.0 & 0.0 & 0.7 & 18.2 & 21.7 & 10.2 & \\
\hline & Part & Treatment (T) & Interaction (P x T) & \\
& $\mathbf{( P )}$ & & & & & & \\
SEM & 0.0 & 0.2 & & 0.2 & & & \\
CD (5\%) & 0.2 & 0.3 & & 0.4 & & &
\end{tabular}

*Means with similar superscripts are not significantly different from each other

Abbreviations: CK, check, without plant extract; CKA, acetone check (acetone, without plant extract); CKM, methanol check (methanol, without plant extract); $\mathrm{PE}$, petroleum ether, with plant extract, $\mathrm{CHL}$, chloroform with plant extract; ME, methanol, with plant extract

\section{Inhibitory activity of Cassia tora seed-extract against Fusarium oxysporum}

Irrespective of treatments, the stem extract was significantly more suppressive (15.1\%) than seed extract (7.6\%) (Table 2). The trend for inhibition of fungal growth was similar to C. gloeosporioides i.e., Chloroform extract could inhibit the growth of $F$. oxysporum to the maximum extent $(26.2 \%)$ followed by petroleum ether $(12.5 \%)$. The least inhibitory activity was quantified in Methanol extract $(10.9 \%)$ whether it was prepared from stem or seed of C. tora. Interaction (P x T) analysis revealed that stem extract had anti- Fusarium activity than seed which was found maximum and significantly more in chloroform extract $(31.9 \%)$ followed by petroleum ether $(22.1 \%)$. Least activity was recorded in methanol extract of C. tora stem (14.5\%). In case of seed, maximum inhibition of fungal growth was observed when chloroform extract (21.4\%) was used followed by methanol extract $(7.2 \%)$, which was at par with chemical check of acetone as well as methanol (7.1\% each).

Table 2 Percent inhibition of growth of Fusarium oxysporum with different extracts at $0.5 \%$ of stem and seed of Cassia tora

\begin{tabular}{|c|c|c|c|c|c|c|c|}
\hline \multirow[t]{2}{*}{ Part } & \multicolumn{6}{|c|}{ Treatments } & \multirow{2}{*}{ Mean } \\
\hline & CK & CKA & CKM & PE & $\mathrm{CHL}$ & ME & \\
\hline Stem & $0.0^{\mathrm{a}}$ & $14.5^{\mathrm{bc}}$ & $7.3^{\text {de }}$ & $22.1^{\mathrm{e}}$ & $31.9^{\mathrm{ef}}$ & $20.5^{d}$ & 15.1 \\
\hline Seed & $0.0^{\mathrm{a}}$ & $7.1^{\mathrm{bc}}$ & $7.1^{\mathrm{cd}}$ & $2.9^{\text {ef }}$ & $21.4^{\mathrm{fg}}$ & $7.2^{\mathrm{h}}$ & 7.6 \\
\hline \multirow[t]{2}{*}{ Mean } & 0.0 & 10.8 & 7.2 & 12.5 & 26.7 & 10.9 & \\
\hline & Part (P) & \multicolumn{2}{|c|}{ Treatment $(T)$} & \multicolumn{3}{|c|}{ Interaction $(P \times T)$} & \\
\hline SEM & 0.0 & 0.2 & & 0.2 & & & \\
\hline $\begin{array}{l}C D \\
(5 \%)\end{array}$ & 0.3 & 0.5 & & 0.6 & & & \\
\hline
\end{tabular}

\section{Inhibitory activity of Cassia tora seed-extract against Ganoderma lucidum}

The growth of Ganoderma lucidum was more inhibited (16.3\%) when treated with the stem extract than seed extract of C. tora, whether it was prepared in any of the organic solvent (Table 3). However, contrary to the previous results, the growth of this fungus was suppressed in the Petroleum Ether extract (37.3\%). Chloroform extract had significantly more inhibitory activity (18.1\%) than Methanol (8.0\%) but it had significantly less than Petroleum Ether extract irrespective of plant part used for extraction. The interaction analysis shows that the maximum anti-Ganoderma activity was seen in Petroleum Ether extract of the C. tora seed (45.8). However in general, stem extract had more activity for example chloroform and methanol extract had inhibited the fungus up to 36.2 and 14.5 percent respectively.

Table 3 Percent inhibition of growth of Ganoderma lucidum with different extracts at $0.5 \%$ of stem and seed of Cassia tora

\begin{tabular}{lllllllll}
\hline Part & \multicolumn{2}{l}{ Treatments } & & & & & Mean \\
\hline & CK & CKA & CKM & PE & CHL & ME & \\
\cline { 2 - 7 } Stem & $0.0^{\mathrm{a}}$ & $11.0^{\mathrm{bc}}$ & $7.4^{\mathrm{d}}$ & $28.8^{\mathrm{d}}$ & $36.2^{\mathrm{de}}$ & $20.5^{\mathrm{d}}$ & 16.3 \\
Seed & $0.0^{\mathrm{a}}$ & $7.1^{\mathrm{bc}}$ & $0.0^{\mathrm{de}}$ & $45.7^{\mathrm{fg}}$ & $0.0^{\mathrm{hi}}$ & $7.2^{\mathrm{h}}$ & 9.0 \\
Mean & 0.0 & 9.0 & 3.7 & 37.3 & 18.1 & 8.0 & \\
\hline \multicolumn{5}{c}{} & Part (P) & Treatment (T) & Interaction (P x T) & \\
\hline SEM & 0.1 & 0.2 & & 0.3 & & & \\
CD & 0.4 & 0.6 & & 0.9 & & & \\
(5\%) & & & & & & & & \\
\hline
\end{tabular}

\section{Discussion}

In the present study, it was found that extraction of Cassia tora in various polar and nonpolar solvents resulted in high amount of extractives in polar solvent than those obtained in organic solvents individually. While testing the efficacy of Petroleum Ether extract of seeds of C. tora against C. gloeosporioides (Table 4) it was observed that irrespective of treatments, the $1.5 \%$ extract solution significantly inhibited the growth of test fungi $(28.0 \%)$ than $1.0 \%$ (20.3\%). The Chloroform extract of the C. tora seeds was found to have more antifungal potency (66.9\%) than Petroleum Ether (39.5\%), irrespective of difference in concentrations. Similar results were found for Ethanol and Chloroform extracts of Sapindus mukorossi against clinical isolates of Yeast and Candida albicans and C. non-albicans. ${ }^{6,7}$ The interaction of concentration of the extracts with treatments revealed that $1.5 \%$ concentration of Petroleum Ether as well as Chloroform inhibited more than $50 \%$ growth of C. gloeosporioides (57.3\% and $68.4 \%$, respectively); and the same was true for the lower concentration of $1.0 \%$ of Chloroform $65.4 \%$ though all these values were statistically exclusive to each other. Irrespective of the treatments, the higher concentration of the extract of $C$. tor $a$ inhibited the growth of $F$. oxysporum significantly more (20.0) than lower concentration of treatment (12.9\%) (Table 5) similar to the effect on C. gloeosporioides. However, plant extract in Petroleum Ether proved significantly better (35.7\%) than that of Chloroform (25.1\%), even at lower concentration. The Concentration versus Treatment Interaction $(\mathrm{C} \times \mathrm{T})$ showed maximum inhibition of the $F$. oxysporum at higher concentration of the Chloroform extract (42.6). However, in case of Petroleum Ether extract, no significant difference in arrest of growth of 
the fungi was observed between lower concentration of 1.0 and higher concentration of 1.5 percent ( 35.6 and $35.8 \%$ inhibition respectively)

Table 4 Percent inhibition of growth of Colletotrichum gloeosporiodes with different extract of seeds of Cassia tora

\begin{tabular}{llllllll}
\hline Con.(\%) & \multicolumn{2}{l}{ Treatments } & & & & Mean \\
\hline & CK & CKA & CKM & PE & CHL & \\
\cline { 2 - 6 } 1.0 & $0.0^{\mathrm{a}}$ & $14.3^{\mathrm{bc}}$ & $0.0^{\mathrm{de}}$ & $28.8^{\mathrm{fg}}$ & $21.6^{\mathrm{h}}$ & 20.3 \\
1.5 & $0.0^{\mathrm{a}}$ & $14.4^{\mathrm{bc}}$ & $0.0^{\mathrm{de}}$ & $45.7^{\mathrm{fg}}$ & $57.3^{\mathrm{g}}$ & 28.0 \\
Mean & 0.0 & 14.3 & 0.0 & 37.3 & 39.5 & \\
\hline \multirow{4}{*}{ Con(C) } & Treatment & Interaction (C x T) & \\
\cline { 2 - 5 } & SEM & 0.1 & 0.05 & 0.1 & & & \\
CD (5\%) & 0.2 & 0.1 & 0.3 & & & \\
\hline
\end{tabular}

Table 5 Percent inhibition of Fusarium oxysporum with different extract of seeds of Cassia tora

\begin{tabular}{|c|c|c|c|c|c|c|}
\hline \multirow[t]{2}{*}{ Con.(\%) } & \multicolumn{5}{|c|}{ Treatments } & \multirow[t]{2}{*}{ Mean } \\
\hline & CK & CKA & CKM & PE & $\mathrm{CHL}$ & \\
\hline 1.0 & $0.0^{\mathrm{a}}$ & $14.5^{\mathrm{bc}}$ & $7.3^{\mathrm{de}}$ & $35.6^{\text {ef }}$ & $21.6^{\mathrm{h}}$ & 12.9 \\
\hline 1.5 & $0.0^{\mathrm{a}}$ & $14.5^{\mathrm{bc}}$ & $7.3^{\mathrm{de}}$ & $35.8^{\mathrm{e}}$ & $42.6^{\mathrm{e}}$ & 20.0 \\
\hline \multirow[t]{2}{*}{ Mean } & 0.0 & 14.5 & 7.3 & 35.7 & 25.1 & \\
\hline & $\operatorname{Con}(C)$ & $\begin{array}{l}\text { Treatment } \\
\text { (T) }\end{array}$ & \multicolumn{4}{|c|}{ Interaction $(C \times T)$} \\
\hline SEM & 0.1 & 0.1 & 0.2 & & & \\
\hline CD (5\%) & 0.3 & 0.2 & 0.5 & & & \\
\hline
\end{tabular}

The concentrations, irrespective of treatments showed similar trends as in previous case, i.e., higher concentration of $1.5 \%$ of the Cassia tora seed-extract strongly inhibited growth of G. lucidum $(10.0 \%)$ than lower concentration (7.2\%) (Table 6). The Chloroform extract of $C$. tora seed-extract had highest and significantly strong antifungal activity $(32.1 \%)$ than any other treatment and irrespective of seed-extract concentrations. While studying the $\mathrm{C} \times \mathrm{T}$, the maximum antifungal activity was detected only in the Chloroform extract $(28.5 \%$ inhibition at $1.0 \%$ concentration and $35.8 \%$ inhibition at $1.5 \%$ concentration). Mukherjee et al. \& Jain et al. ${ }^{8,9}$ studied that the Chloroform fraction of $C$. tora seed-extract showed strong fungicidal activity against Botrytis cinerea, Erysiphe graminis, Phytophthora infestans, Rhizoctonia solani. The mode of antifungal activity of $C$. tora extracts on the pathogenic fungi remains a valid query on these findings. Phongpaichit et al. ${ }^{10}$ tested the antifungal activities of crude methanol extracts from leaves of Cassia tora on the pathogenic fungus Microsporum gypseum and on microscopic observations found that the extract affected conidial germination, and the hyphae and macroconidia were shrunken and collapsed, which might be due to cell fluid leakage. ${ }^{11}$
Table 6 Percent inhibition of Ganoderma lucidum with different extract of seed of Cassia tora

\begin{tabular}{|c|c|c|c|c|c|c|}
\hline \multirow[t]{2}{*}{ Con.(\%) } & \multicolumn{5}{|c|}{ Treatments } & \multirow[t]{2}{*}{ Mean } \\
\hline & CK & CKA & CKM & PE & $\mathrm{CHL}$ & \\
\hline 1.0 & $0.0^{\mathrm{a}}$ & $0.0^{\mathrm{ab}}$ & $7.3^{\mathrm{cd}}$ & $0.0^{\text {ef }}$ & $28.5^{8}$ & 7.2 \\
\hline 1.5 & $0.0^{\mathrm{a}}$ & $0.0^{\mathrm{ab}}$ & $7.3^{\mathrm{cd}}$ & $7.1^{\mathrm{e}}$ & $35.8^{\mathrm{e}}$ & 10.0 \\
\hline \multirow[t]{2}{*}{ Mean } & 0.0 & 0.0 & 7.4 & 3.6 & 32.1 & \\
\hline & Con(C) & $\begin{array}{l}\text { Treatment } \\
\text { (T) }\end{array}$ & \multicolumn{4}{|c|}{ Interaction $(\mathrm{C} \times \mathrm{T})$} \\
\hline SEM & 0.1 & 0.0 & 0.1 & & & \\
\hline CD (5\%) & 0.1 & 0.1 & 0.2 & & & \\
\hline
\end{tabular}

\section{Acknowledgements}

None.

\section{Conflict of interest}

Authors declare that there is no conflict of interest.

\section{References}

1. Grainge M, Ahmed S, Mitchell WC, et al. Plant species reportedly possessing pest-control properties. A database resource systems. Honolulu: Institute East-West Center; 1994:8-10.

2. Anonymous. Wealth of India, Raw Materials, CSIR, New Delhi; 1950.

3. Sharma BR, Kumar V, Soni PL. Carboxymethylation of Cassia tora gum. Applied Polymer. 2003;89:3216-3219.

4. Soni, PL. Pal R. Industrial gum from Cassia tora seeds. Trends in Carbohydrate Chemistry. 1996;2:33-44.

5. Onalapo JA, Rai PP, Sokomba EN. Preliminary studies on the antimicrobial activities of Cassia tora and Cassia occidentalis medicinal plants. New Vistas of Research. 1993;11:533-536.

6. Ibrahim M, Khan AA, Tiwari SK, et al. Antimicrobial activity of Sapindus mukorossi and Rheum emodi extracts against Helicobacterium pylori in in vivo studies. World J Gastroenterol. 2006;12(44):7136-7142.

7. Tsuzuki JK, Svidizinski TIE, Shinobu CS, et al. Antifungal activity of the extracts and saponins from Sapindus saponaria L. Anais da An Acad Bras Cienc. 2007;79(4):577-583.

8. Jain S, Patil UK. Phytochemical and pharmacological profile of Cassia tora Linn.- An overview. Indian Journal of Natural Products and Resources. 2010;1:430-437.

9. Mukharjee PK, Saha K, Das J. Antifungal screening of Cassia tora Linn. (Fam. Leguminosae). Phytotherapy Research. 1998;10:521-522.

10. Phongpaichit S, Pujenjob N, Rukachaisirikul V, et al. Antifungal activity from leaf extracts of Cassia alata L, Cassia fistula L and Cassia tora L. Songklanakarin. Journal of Science and Technology. 2004;26:741-748.

11. The Wealth of India. A Dictionary of Indian Raw Materials and Industrial Products. Ed. New Delhi, India: Council of Scientific and Industrial Research; 1951. 